ISSN: $1410-8917$

Jurnal Kimia

Sains \&

Aplikasi
Jurnal Kimia Sains dan Aplikasi Journal of Scientific and Applied Chemistry

Journal homepage: http://ejournal.undip.ac.id/index.php/ksa

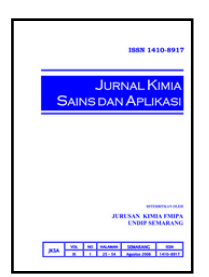

\title{
Isolasi, Identifikasi dan Uji Sitotoksik Senyawa Alkaloid Daun Ketapang yang Sudah Menguning (Terminalia cattapa Linn)
}

\author{
Ferdian Cahya Prima $^{a}$, Dewi Kusrini ${ }^{a^{*}}$, Enny Fachriyah ${ }^{a}$ \\ a Organic Chemistry Laboratory, Chemistry Department, Faculty of Sciences and Mathematics, Diponegoro University, Jalan Prof. \\ Soedarto, Tembalang, Semarang \\ * Corresponding author: dewi.kusrini@live.undip.ac.id
}

\begin{tabular}{|c|c|}
\hline Article Info & Abstract \\
\hline & Isolation of indole alkaloid compounds From yellow leaves ketapang (Terminalia Cattapa \\
\hline $\begin{array}{l}\text { Keywords: } \\
\text { Terminalia cattapa Linn, } \\
\text { alkaloids, Cytotoxic, } \\
\text { Indole, UV-Vis } \\
\text { spectrophotometry }\end{array}$ & $\begin{array}{l}\text { Linn) had been carried out with acid-base extraction method. The results of isolation, it } \\
\text { was obtained the total alkaloid compounds of } 1.423 \mathrm{~g} \text { (yield } 0.287 \% \text { ). The analysis using } \\
\text { UV-Vis spectrophotometry showed absorption at a wavelength of } 206 \text { and } 224 \mathrm{~nm} \text {, } \\
\text { which indicated that the alkaloid compound had an indole framework. Cytotoxic test } \\
\text { obtained a } \text { LC }_{50} \text { value of } 157.004 \mathrm{ppm}\end{array}$ \\
\hline
\end{tabular}

\section{Abstrak}

Kata Kunci:

Terminalia cattapa Linn, Alkaloid, Sitotoksik, Indol, Spektrofotometri UV-Vis.

\begin{abstract}
Telah dilakukan proses isolasi senyawa alkaloid indol daun ketapang yang sudah menguning (Terminalia Cattapa Linn) dengan metode ekstraksi Asam-Basa. Hasil isolasi diperoleh senyawa alkaloid total sebesar 1,423 gram (percent 0,287\%). Analisis menggunakan spektrofotometri UV-Vis menunjukkan adanya serapan pada panjang gelombang 206 dan $224 \mathrm{~nm}$, yang mengindikasikan bahwa senyawa alkaloid memiliki kerangka dasar indol. Uji sitotoksik diperoleh harga $\mathrm{LC}_{50}$ sebesar 157,004 ppm.
\end{abstract}

\section{Pendahuluan}

Indonesia merupakan salah satu negara tropis yang dikenal memiliki keanekaragaman tumbuhan yang sangat besar, keanekaragaman tumbuhan Indonesia tercatat mencapai \pm 38.000 jenis. Salah satunya adalah ketapang (Terminalia cattapa Linn), selama ini masyarakat tidak banyak mengetahui tentang potensipotensi dan kandungan-kandungan senyawa bermanfaat yang dimiliki oleh ketapang. Ketapang merupakan salah satu tanaman yang masuk dalam kategori famili Combretaceae yang tersebar merata di seluruh Indonesia. Berdasarkan penelitian yang selama ini telah dilakukan, tercatat di dalam daun ketapang terdapat kandungan senyawa metabolit sekunder seperti flavonoid [1], polifenol, saponin, triterpen dan tannin [2]. Penelitian tentang tanaman famili combretaceae pada umumnya mengidentifikasi tentang adanya kandungan senyawa alkaloid.

Penelitian yang selama ini telah dilakukan, masih sedikit sekali yang menggali potensi senyawa alkaloid di dalam daun ketapang, dan juga mayoritas didominasi dengan penggunaan daun ketapang hijau. Daun ketapang yang sudah menguning selama ini kurang mendapat perhatian. Diharapkan dari penelitian akan dihasilkan senyawa alkaloid daun ketapang yang sudah menguning, dan dapat diidentifikasi jenisnya serta dapat diketahui sifat toksiknya.

\section{Metode Penelitian}

Bahan

Daun ketapang yang sudah menguning, pelarut nheksana dan etanol teknis diperlukan pada proses maserasi, asam klorida p.a, amoniak p.a, etil asetat, diperlukan dalam isolasi alkaloid total. Kemudian pereaksi Meyer $\left[\mathrm{HgCl}_{2}+\mathrm{KI}+\mathrm{H}_{2} \mathrm{O}\right]$ dan Dragendorf $\left[\mathrm{Bi}\left(\mathrm{NO}_{3}\right)_{3}+\mathrm{HNO}_{3}+\mathrm{KI}+\mathrm{H}_{2} \mathrm{O}\right]$ diperlukan untuk uji alkaloid.

\section{Pembuatan Serbuk}

Daun ketapang yang sudah menguning diperoleh dari lingkungan Universitas Diponegoro, dicuci, diiris 
tipis-tipis, dan dikeringkan dengan cara dianginanginkan sehingga diperoleh daun ketapang kering kemudian dihaluskan untuk mendapatkan serbuk daun ketapang kering.

\section{Isolasi Alkaloid Total}

Serbuk daun ketapang sebanyak 500 gram dimaserasi dengan pelarut $\mathrm{n}$-heksana sampai jernih, kemudian dipisahkan ekstrak dengan residunya. Residu yang diperoleh dibiarkan di udara terbuka untuk menghilangkan sisa pelarut, kemudian dimaserasi lebih lanjut menggunakan pelarut etanol sampai jernih. Ekstrak yang diperoleh kemudian dipekatkan dengan rotary evaporator sehingga diperoleh ekstrak kental. Ke dalam ekstrak kental ini ditambahkan $\mathrm{HCl} 2 \mathrm{M}$ sampai diperoleh $\mathrm{pH}$ 3. Larutan asam selanjutnya diekstraksi dengan etil asetat sehingga diperoleh dua lapisan, lapisan etil asetat dan lapisan asam, kemudian dipisahkan. Ke dalam lapisan asam kemudian ditambahkan $\mathrm{NH}_{4} \mathrm{OH}$ sampai diperoleh $\mathrm{pH}$ 8-9, selanjutnya diekstraksi dengan etil asetat. Sehingga diperoleh lapisan basa dan lapisan etil asetat, kemudian dipisahkan. Lapisan etil asetat yang diperoleh selanjutnya diuapkan hingga diperoleh isolat berupa padatan yang merupakan alkaloid total. Selanjutnya alkaloid total diuji menggunakan pereaksi Mayer dan Dragendrof untuk mengetahui apakah hasil isolasi merupakan senyawa alkaloid.

Penentuan Jumlah Komponen dan Pemisahan Alkaloid dengan Kromatografi Lapis Tipis serta Kromatografi Preparatif

Terhadap isolat yang diperoleh dilakukan kromatografi lapis tipis dengan pengembang berupa campuran $\mathrm{n}$-heksanaa p.a, etil asetat, p.a dan kloroform p.a dengan berbagai perbandingan volume dan fase diam berupa silika gel $60 \mathrm{GF}_{254}$ untuk menentukan jumlah komponen di dalam isolat. Setelah jumlah komponen diketahui dilakukan pemisahan komponen dengan metode Kromtografi Lapis Tipis Preparatif.

Uji Kemurnian Senyawa Alkaloid

Uji kemurnian dilakukan dengan metode KLT dengan berbagai pelarut.

Identifikasi Hasil Isolasi

Isolat diidentifikasi

menggunakan

Spektrofotometri UV-Vis.

\section{Uji Sitotoksik Alkaloid Total dengan Metode BSLT}

Alkaloid total yang diperoleh selanjutnya dilakukan uji sitotoksik menggunakan larva Artemis salina L. dengan konsentrasi 1000, 100 dan 10 ppm dengan menggunakan tween-20 sebanyak $5 \mu \mathrm{L}$ dan air garam. Ke dalam setiap konsentrasi sampel dimasukan 10 ekor larva Artemia salina. Setelah 24 jam, jumlah larva yang mati dihitung, selanjutnya data yang diperoleh diolah dengan menggunakan metode probit analisis untuk menentukan nilai $\mathrm{LC}_{50}$. Uji sitotoksik dengan metode BSLT dilakukan dengan langkah-langkah berikut :

\section{Pembuatan medium penetasan}

Sebanyak 3,8 gram garam krosok dilarutkan dalam $100 \mathrm{~mL}$ aquades, kemudian dikocok dan kemudian disaring, sehingga menjadi air laut buatan.

\section{Pembuatan variasi konsentrasi sampel}

Sebanyak 0,00625 $\mathrm{g}$ dari senyawa alkaloid total dihomogenkan dengan tween-20 sebanyak $5 \mu \mathrm{L}$ dan diencerkan dengan air laut buatan, selanjunya dibuat konsentrasi 1000, 100, dan 10 ppm.

\section{Pembuatan larutan blanko}

Sebanyak $5 \mu \mathrm{L}$ tween-20 dilarutkan ke dalam air laut buatan dan diencerkan menggunakan labu pengencer dengan volume $50 \mathrm{~mL}$.

\section{Penetasan telur}

Medium penetasan yang sudah disiapkan kemudian ditempatkan dalam tangki penetas kemudian diberi telur Artemia salina. Setelah larva menetas dan berumur 2 x 24 jam sudah bisa dipakai untuk uji sitotoksik.

Penentuan ambang kematian Artemia salina L.

Ambang kematian Artemia salina ditentukan dengan memasukan $5 \mathrm{~mL}$ larutan uji dengan konsentrasi 1000, 100 dan 10 ppm masing-masing dalam botol vial yang berbeda. Sebanyak 10 ekor larva Artemia salina dimasukan masing-masing ke dalam botol vial tersebut untuk diuji, botol vial dijaga agar tetap mendapat penerangan. Jumlah Artemia salina yang mati dalam tiap botol vial dihitung selama 24 jam perlakuan. Uji sitotoksik ini dilakukan dengan pengulangan 3 kali. Data yang diperoleh diolah dengan program probit analisys untuk menentukan nilai $\mathrm{LC}_{50}$.

\section{Hasil dan Pembahasan}

Proses Isolasi senyawa Alkaloid Daun Ketapang yang sudah menguning dihasilkan isolat alkaloid total berupa padatan berwarna coklat. Untuk mengetahui apakah isolat merupakan senyawa alkaloid dilakukan uji alkaloid menggunakan pereaksi Mayer dan pereaksi Dragendorf. Hasil uji alkaloid menunjukkan hasil positif, pada penambahan pereaksi Mayer ditunjukkan dengan adanya kabut putih, dan pada penambahan pereaksi Dragendorf ditunjukkan dengan adanya endapan berwarna coklat. Perkiraan reaksi yang terjadi pada uji Mayer ditunjukkan pada reaksi berikut ini [3]:

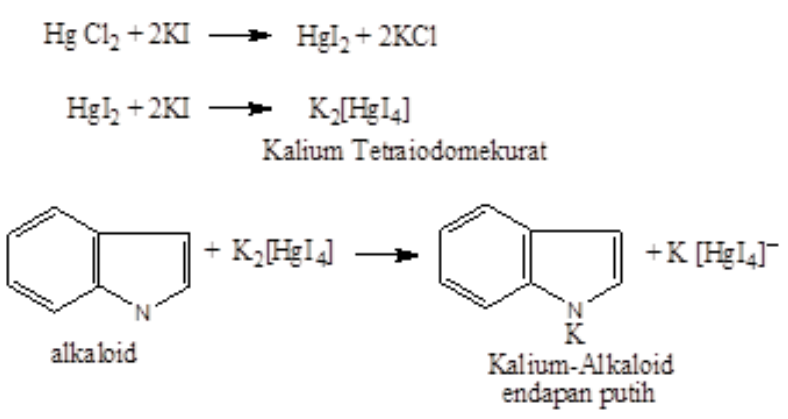

Perkiraan reaksi pada uji Dragendorff ditunjukkan pada Gambar di bawah ini [3]: 


$$
\begin{aligned}
\mathrm{Bi}\left(\mathrm{NO}_{3}\right)_{3}+3 \mathrm{KI} & \rightarrow \underset{\text { coklat }}{\mathrm{BiI}_{3}+3 \mathrm{KNO}_{3}} \\
\mathrm{BiI}_{3}+\mathrm{KI} & \underset{\mathrm{K}\left[\mathrm{BiI}_{4}\right]}{\rightarrow \text { kalium tetraiodomerkurat }}
\end{aligned}
$$

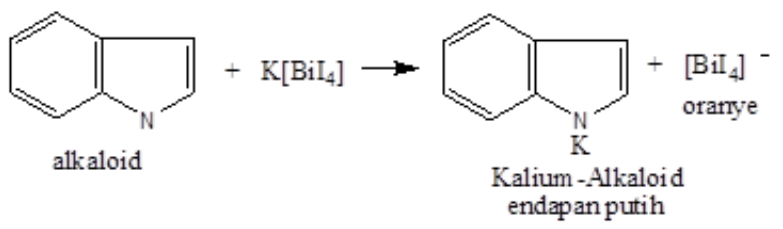

Untuk mengetahui berapa banyak komponen senyawa alkaloid total dilakukan Kromatografi Lapis Tipis dengan menggunakan berbagai pelarut. Berdasarkan analisis KLT menggunakan eluen terbaik kloroform:benzena 1:9 diperoleh 3 noda, yaitu noda 1 berwarna biru (Rf: 0,403 ), noda 2 berwarna hijau (Rf: $0,315)$, noda 3 berwarna biru muda (Rf: 0,122 ), dengan noda dominan pada noda 1. Selanjutnya dilakukan kromatografi lapis tipis preparatif untuk memisahkan ketiga noda tersebut. Dari 3 noda yang diperoleh, noda yang paling dominan adalah noda 1 yang berwana biru, sehingga noda tersebut dianalisis/dipisahkan, dan dilanjutkan uji kemunian dengan berbagai pelarut. Uji kemurnian dilakukan pada noda 1 bewarna biru hasil pemisahan KLT preparatif. Uji kemurnian dilakukan dengan pelarut benzena:klorofom (9:1). Hasil uji kemurnian tersebut masih menunjukkan adanya 5 noda berwarna biru dengan noda dominan noda A3 dan noda A5, Sehingga perlu dilakukan pemisahan kembali dengan KLT preparatif. Hasil pemisahan tersebut kemudian dilakukan uji kemurnian kembali. Hasil uji kemurnian tersebut masih menunjukkan adanya 5 noda berwarna biru dengan noda dominan noda A3 dan noda A5, Sehingga perlu dilakukan pemisahan kembali dengan KLT preparatif. Hasil pemisahan tersebut kemudian dilakukan uji kemurnian kembali.

Pada Uji kemurnian selanjutnya masih selalu menghasilkan 5 noda, kondisi ini berlanjut sampai dilakukan uji kemunian yang ke-5 yaitu selalu menunjukkan keadaan yang hampir serupa. Berikut ini merupakan gambar seluruh uji kemunian, menunjukan hasil yang hampi serupa:
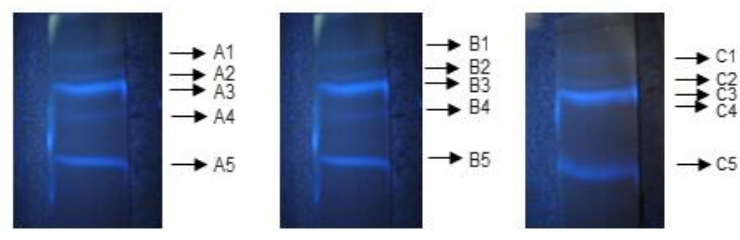

a. Uji Kemurnian ke-1 b. Uji Kemunian ke-2 c. Uji Kemurnian ke-3
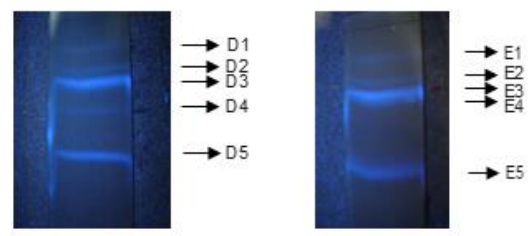

d. Uji Kemunian ke-4

e. Uji Kemunian Ke-5

Gambar 1. Hasil seluruh Uji Kemunian senyawa alkaloid

Hasil seluruh uji kemurnian menunjukan hasil yang cenderung sama yaitu selalu menghasilkan 5 noda berwarna biru dengan noda dominan pada noda 3 dan noda 5 . Hal ini mengindikasikan dalam noda tersebut masih mengandung beberapa komponen senyawa alkaloid. Mengacu pada hasil KLT Preparatif terakhir diputuskan diambil noda paling dominan yaitu noda E5 pada uji kemurnian yang terakhir dengan petimbangan noda diharapkan sudah cukup murni.

Hasil analisis isolat noda E5 dengan spektroskopi UV-Vis dipaparkan pada gambar 2 sebagai berikut:

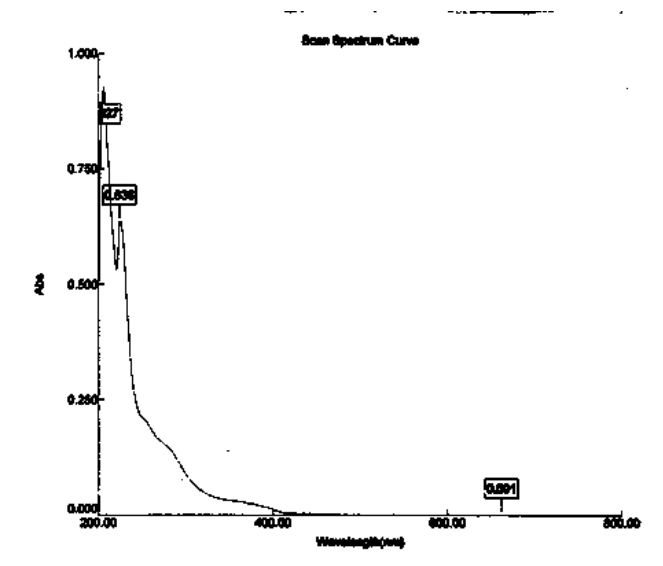

Gambar 2. Spektra Uv-Vis Isolat noda E5

Hasil dianalisis spektrofotometri UV-Vis menunjukkan adanya serapan pada panjang gelombang 206 dan $224 \mathrm{~nm}$, yang mengindikasikan bahwa senyawa alkaloid memiliki kerangka dasar indol. Sedangkan dari hasil uji Sitotoksik terhadap isolat alkaloid total dengan menggunakan metode BSLT dihasilkan harga LC50 sebesar 157,004 ppm hal ini mengindikasikan senyawa alkaloid tersebut bersifat tidak toksik [4]. Berikut ini merupakan struktur alkaloid dengan kerangka dasar indol:<smiles>c1ccc2[nH]ccc2c1</smiles>

Gambar 3. Alkaloid dengan Kerangka dasar Indol [5]

\section{Kesimpulan}

Hasil analisis isolat alkaloid murni diindikasikan senyawa alkaloid tersebut memiliki kerangka dasar indol. Hasil uji sitotoksik dengan BSLT menunjukkan bahwa senyawa alkaloid total daun ketapang yang sudah menguning memiliki harga LC50 sebesar 157,004 ppm yang berarti tidak toksik.

\section{Daftar Pustaka}

[1] A Mann, BB Barnabas, II Daniel, The effect of methanolic extracts of Anogeissus leiocarpus and Terminalia avicennioides on the growth of some food-borne microorganisms, Aust J Basic Appl Sci, 4, 12, (2010) 6041-6045

[2] Nantarika Chansue, Nongnut Assawawongkasem, The in vitro antibacterial activity and ornamental fish toxicity of the water extract of Indian almond leaves (Terminalia catappa Linn.), KKU Veterinary Journal, 18, 1, (2011) 36-45 
[3] Soerya Dewi Marliana, Venty Suryanti, Skrining fitokimia dan analisis kromatografi lapis tipis komponen kimia buah labu siam (Sechium edule Jacq. Swartz.) dalam ekstrak etanol, Biofarmasi, 3, 1, (2005) 26-31

[4] MJ Moshi, E Innocent, JJ Magadula, DF Otieno, A Weisheit, PK Mbabazi, RSO Nondo, Brine shrimp toxicity of some plants used as traditional medicines in Kagera region, north western Tanzania, Tanzania journal of health research, 12, 1, (2010) 63-67 http://dx.doi.org/10.4314/thrb.v12i1.56287

[5] Sjamsul A Achmad, Kimia Organik Bahan Alam, Jakarta: Karunika, (1986) 